\title{
Transgenic Tomato Plants Ectopically Expressing BrRZFP1 Gene Encoding C3HC4-type RING Zinc Finger Protein
}

\author{
Yu-Jin Jung, Yong Gu Cho ${ }^{2}$, Ill Sup Nou ${ }^{3}$, Kwon Kyoo Kang ${ }^{1}$ * \\ ${ }^{1}$ Department of Horticulture, Hankyong National University, Ansung, Kyonggi-do 456-749, Korea \\ ${ }^{2}$ Department of Crop Science, Chungbuk National University, Cheongju 361-763, Korea \\ ${ }^{3}$ Department of Horticulture, Sunchon National University, 413 Jungangno, Suncheon, Jeonnam 540-742, Korea
}

\begin{abstract}
C3HC4-type RING zinc finger proteins are known to be essential in the regulation of plant processes, including responses to abiotic stress. In order to explore the potential of the BrRZFPl gene to enhance tolerance toward multiple stresses in different host plant genomes, we generated transgenic tomato (Solanum lycopersicum L. cv. Goldenbell) plants. The tomato plants overexpressing BrRZFPl acquired a higher tolerance to drought stress. However, the transgenic plants did not appear to be more cold tolerant than the WT, in any tested condition. The data obtained indicate that the specificity and the degree of $B r R Z F P 1$ activity depend on the host genomic background. In physiological assessment of salt stress tolerance, transgenic plants showed more dry matter accumulation and maintained significantly higher levels of leaf chlorophyll content along with increasing levels of salt stress than the wild type plants. This study shows that BrRZFP1 is a candidate gene in the engineering of crops for enhanced drought and salt stress tolerance.
\end{abstract}

Keywords $\quad B r R Z F P 1$ gene, Abiotic stresses, Transgenic plants, Tomato

\section{INTRODUCTION}

The rapidly growing world population has made it necessary to limit the losses of crop productivity due to plant responses to environmental stress conditions, such as elevated or low temperatures, drought, salinity, poor soil nutrition, radiation, oxidative stress, and heavy metals. These abiotic factors activate an array of signaling pathways that ultimately lead to plant adaptation to stress, either through post-transcriptional or post-translational regulation (Mazzucotelli et al. 2008). Alternative splicing, degradation or accumulation of stress-related transcripts define the plant response to stresses at the mRNA level, whereas protein phosphorylation and dephosphorylation, ubiquitination, and sumoylation are some of the adaptive responses at the protein level (Mazzucotelli et al. 2008). To develop plant cultivars inherently resistant to abiotic stress would help secure crop production. However, progress in genetic improvement of crops for abiotic-limiting environments is slow and more limited (Evenson and Gollin 2003), due to the lack of knowledge about the physiological processes limiting growth under abiotic stress conditions, poor understanding of abiotic stress tolerance mechanism, and lack of efficient techniques for screening breeding materials for abiotic stress tolerance (Khush 2001).

In recent years, transcription factors are known to be essential regulators of plant cellular and physiological responses to environmental stimuli. Several plant transcription factors, regulating the biotic and abiotic stress response, have been identified and the function of some of them (i.e. CBFs/DREBs, ZFPs and SCOF-1) in freezing and cold tolerance has been demonstrated (Xiong et al. 2002; Tran et al. 2007; Cong et al. 2008; Zheng et al. 2009; Golldack et al. 2011). Zinc finger proteins (ZFPs) are one of the best studied transcription factor families, playing important roles in various cellular functions, including transcriptional activation, regulation of apoptosis and protein folding and assembly (Laity et al. 2001). The zinc-binding motifs of

Received March 6, 2014; Revised March 11, 2014; Accepted March 11, 2014; Published March 31, 2014

*Corresponding author Kwon Kyoo Kang, kykang@hknu.ac.kr, Tel: +82-31-670-5104, Fax: +82-31-670-5100 
ZFPs vary widely in structure, as well as function, which can range from DNA or RNA binding to protein-protein interactions and membrane association (Laity et al. 2001). One group of ZFPs contains the RING-finger motif, which consists of 40-60 amino acid residues that bind two atoms of zinc, and can be further divided into two general classes: RING-H2 (C3H2C3) and RING-HC (C3HC4) ZFPs (Freemont et al. 1991; Freemont 1993). Since their initial identification, many genes encoding RING finger proteins have been isolated from a variety of organisms, including animals, plants and viruses, and have been shown to possess a diverse range of biological functions (Saurin $e t$ al. 1996; Kam et al. 2007; Ma et al. 2009). Plants must respond to various abiotic stresses, such as high salinity, high and low temperatures and drought, in order to survive. These adverse environmental stresses limit crop growth and productivity, and also induce expression of a variety of genes, including ZFPs (Xiong et al. 2002; Bartels and Sunkar 2005; Islam et al. 2009). Previous studies of RING zinc finger proteins from various plants show that they are linked to a range of environmental stress processes, e.g. drought and other abiotic stresses, as well as disease resistance (Wang et al. 2006; Cheung et al. 2007; Kam et al. 2007; Zhang et al. 2007; Yang et al. 2008; Islam et al. 2009). Additionally, ZFPs function in the formation, development or signaling processes linked to stress processes, e.g. light perception, peroxisome formation and during seed and root development (Pepper and Chory 1997; Xu and Li 2003; Chen and Ni 2006; Wang et al. 2006; Prestele et al. 2010). It is important to note that RING proteins can also function as E3 ubiquitin ligase proteins, which also have a strong role in many of the same stressrelated processes. The aim of this work was to investigate the possibility to utilize the BrRZFPl gene to enhance tolerance towards multiple environmental stresses in tomato (Solanum lycopersicum L.), one of the major agricultural commodities, characterized by a high sensitivity to stresses. Namely, we analyzed transformed tomato plants for tolerance to chilling, drought and resistance to pathogens. We found that $B r R Z F P 1$ is able to improve the tolerance to some of the assayed drought stress, but not to chilling. In addition, to test if the constitutive expression of BrRZFP1 modifies the tomato fruit quality, we analyzed the soluble solids content (SSC), skin color, lycopene synthesis and ethylene production.

\section{MATERIALS AND METHODS}

\section{Plant materials}

Tomato plants (Solanum lycopersicum L. Mill. cv. Goldenbell) were grown in a controlled environment chamber at $25^{\circ} \mathrm{C}$, with a $16 \mathrm{~h} / 8 \mathrm{~h}$ photoperiod, a light intensity of $120 \mu \mathrm{mol} \mathrm{m}^{2} \mathrm{~s}^{1}$ and $70 \%$ relative humidity. For transformation, the tomato seeds were surface-sterilized by immersion for $1 \mathrm{~min}$ in 70\% ethanol, followed by $5 \mathrm{~min}$ in $2.5 \% \mathrm{NaOCl}$ supplied with $0.1 \%$ Tween and washed several times with sterilized distilled water. The seeds were cultured for two days in distilled water and then transferred to Magenta boxes containing $50 \mathrm{~mL}$ of $1 \mathrm{x}$ Murashige and Skoog (MS) salts (Murashige and Skoog 1962), Gamborg B5 vitamins (Gamborg et al., 1968), 2\% sucrose and 0.8\% agar, $\mathrm{pH}$ 5.8. The cultures were maintained in a growth chamber. Eleven days after germination, the cotyledon sections, with the distal and proximal ends cut off, were used for Agrobacterium-mediated transformation.

\section{Construction of plant transformation vector}

The 1,041 bp open reading frame (ORF) of the BrRZFPl cDNA was amplified by polymerase chain reaction (PCR) using the forward primer BrRZFPIFl (5'-ATGCCTTCTTCTGGAGATCCC-3') and the reverse primer BrRZFPIRI (5'-TTAAACAAATGGCATAGTTTTAC-3'). The amplified product was purified and cloned into the pMD-18T vector (Takara, Korea), and digested with BamHI and SacI. Subsequently the resulting fragment was inserted into the $B a m \mathrm{HI}$ and $\mathrm{SacI}$-predigested modified expression vector pCAMBIA2300. The resulting vector, pCAMBIA::BrRZP1, contained the BrRZP1 gene driven by the CaMV35S promoter and terminated by nopaline synthase terminator (Nos). The pCAMBIA:: BrRZP1 was introduced into $A$. tumefaciens strain EHA105 by the freeze-thaw transformation method. Single transformed colony was transferred into liquid bacterial culture medium (LB medium with $50 \mathrm{mg} / \mathrm{L}$ rifampicin, $25 \mathrm{mg} / \mathrm{L}$ streptomycin and $50 \mathrm{mg} / \mathrm{L}$ kanamycin) and shaken at $240 \mathrm{rpm}$ at $28^{\circ} \mathrm{C}$ for two days. The 
suspension was then mixed with sterile glycerol $(1: 1 \mathrm{v} / \mathrm{v})$ and stored at $-70^{\circ} \mathrm{C}$ until use.

\section{Tomato transformation}

Cotyledons from the 2-week-old tomato seedlings grown in the growth chamber were used for cocultivation with $A$. tumefaciens to generate transgenic plants, according to the method of Van Roekel et al. (1993).

\section{Total RNA extraction and RT-PCR analysis}

Total RNA was extracted by using TRIzoll reagent (Invitrogen) from tomato plants grown for four weeks in the greenhouse. Material from the control and treated plants was always collected at 9 a.m., in order to avoid variability in the gene expression due to the circadian clock regulation. The plant samples were immediately frozen in liquid nitrogen. Five micrograms of DNase treated RNA were retrotranscribed to first-strand cDNA with the Super ScriptTM First-Strand Synthesis System for RT-PCR kit (Invitrogen). PCR reactions were then carried out with the following gene-specific primers: BrRZFP 1: (F) 5'-ATGCCTTCTTCTGGAGATCCC-3', (R) 5'-CGACGTTGAATCTCAAGTC AC-3'; Tomato Actin (F) 5'-GTGACAATGG AACTGGAATG-3', (R)5'-AGACGGAGGATAGCGTGAGG-3'. The samples were subjected to 30 amplification cycles under the following annealing conditions: $58^{\circ} \mathrm{C}$ for $B r R Z F P I$ and $65^{\circ} \mathrm{C}$ for Actin DNA. The amplification products were separated by electrophoresis on $1 \%$ agarose gels.

\section{Chilling treatment}

The leaves from 4-week-old plants were layered on the surface of the MS agar medium. The plates were placed in a cabinet for photo inhibition treatments consisting of an irradiance of $750 \mu \mathrm{mol} \mathrm{m}^{2} \mathrm{~s}^{1}$, provided by a $440-\mathrm{W}$ lamp, at a temperature of $4^{\circ} \mathrm{C}$ for $5 \mathrm{~h}$ and $30 \mathrm{~min}$. The chlorophyll fluorescence emission, from the upper surface of the leaves, was measured with a plant efficiency analyser (Hansatech Instruments, Norfolk, UK), according to Tarantino et al. (1999). Before measurements, the leaves were dark-adapted for $30 \mathrm{~min}$ at room temperature. Each experiment was replicated three times and in each experiment the leaves of one plant were assayed three times at different time intervals.

\section{Drought treatment}

To evaluate the drought tolerance of the transgenic tomato lines, the relative water content (RWC) of the transgenic and WT plants leaves was measured. Ten 4-week-old plants for each genotype grown individually in $15 \mathrm{~cm}$ pots were placed at random in a climatic chamber at $24{ }^{\circ} \mathrm{C}, 16 \mathrm{~h} / 8 \mathrm{~h}$ light/dark regime, $60 / 70 \%$ humidity. The earth of the vases was abundantly watered and left to percolate for $24 \mathrm{~h}$. Subsequently, the plants were left dry. Since then $\left(t_{0}\right)$, for every four days, eight leaves of each genotype were randomly collected and weighed (fresh weight, FW). Afterward, the leaves were kept, to become impregnated, on Petri dishes for $24 \mathrm{~h}$ lined with filter paper saturated with demineralized water. They were then weighed (turgid weight, TW) and kept at $70^{\circ} \mathrm{C}$ for $48 \mathrm{~h}$, to determine the dry weight (DW). The RWC was calculated as a percentage of (FW- DW)/(TW- DW). For in vivo assays, 4-week-old WT and transgenic $\mathrm{T}_{1}$ plants were grown in $15 \mathrm{~cm}$ pots and placed at random in a greenhouse $\left(24^{\circ} \mathrm{C}, 16 \mathrm{~h} / 8 \mathrm{~h}\right.$ light $/$ dark regime, $60 / 70 \%$ humidity). The soil contained in the pots was abundantly watered and, subsequently, plants were left dry without watering for 28 days. Then, the plants were watered for 7 days and plant survival was evaluated. We have performed two experiments: in the first one we tested WT, AT1 and AT4 plants; in the second one we used WT, AT2 and AT3 lines. In each experiment, 20 plants/genotype were assayed.

\section{Soluble sugars, proline and amino acid content}

Soluble sugars and proline contents were determined on frozen leaves from the same plants used for in vivo drought assays: leaves were detached from WT and transgenic 4-week-old plants grown under normal conditions and from the same plants after 28 days of water deficit. Three individual plants for each genotype were tested. Plant material was extracted using $0.6 \mathrm{~N}$ perchloric acid, and the supernatant collected after centrifugation at $16000 \mathrm{x}$ g for $15 \mathrm{~min}$. Sucrose, glucose and fructose were quantified using the Boehringer Mannheim kit and the reduction of NADP was monitored at $340 \mathrm{~nm}$. Standard curves of sucrose, glucose and fructose were prepared. On the same extracts, proline concentration was determined as described previously (Mattana et al. 2005). Proline content was 
calculated on the basis of a standard curve of L-Pro. The amino acid content was determined using the method of Moore (1968).

\section{Soluble solids content in fruits}

Juice was squeezed from ripe tomatoes and collected onto a digital Attago N1 refractometer. The soluble solids content (SSC) was measured at $20^{\circ} \mathrm{C}$ and the results were expressed as degrees Brix ( $\left.{ }^{\circ} \mathrm{Brix}\right)$.

\section{Lycopene measurement}

The lycopene standard was purchased from Sigma. A stock solution, dissolving $5 \mathrm{mg}$ lycopene in $10 \mathrm{~mL}$ chloroform, was prepared and sonicated for $20 \mathrm{~min}$. Owing to the lycopene instability, the standard purity was checked by a spectrophotometer, with $\mathrm{E}^{1 \%}{ }_{472 \mathrm{~nm}}=3450$ in hexane. From the stock solution, a 1:250 dilution was prepared in hexane, to a final concentration of $2 \mathrm{mg} / \mathrm{mL}$, and absorbance was measured at $472 \mathrm{~nm}$, using a $1 \mathrm{~cm}$ path length quartz cuvette after blanking with hexane. The purity was calculated as follows: $\%$ Purity $=($ Abs $\times 10000 / 3450 \times C)$ $\times 100 \%$, where $\mathrm{Abs}=$ absorbance units, and $\mathrm{C}=$ standard concentration in $\mathrm{mg} / \mathrm{mL}$. The spectrophotometric purity was then used to correct the concentration of the chromatographic calibration solutions. From the 500 $\mathrm{mg} / \mathrm{mL}$ stock solution in chloroform, standard 1:10, 1:25, 1:50, 1:100 and 1:250 dilutions were prepared with chloroform and methanol (1:1), to create a five point linearity curve for HPLC analysis. To avoid oxidation during the sample preparation, the whole laboratory procedures were conducted under dim light. Each sample was analyzed in duplicates, with triplicate injections for HPLC. Twenty milliliters of $2 \mathrm{~N} \mathrm{HCl} / \mathrm{L}$-ascorbic acid solution were added to $50 \mathrm{mg}$ of sample, into a $50 \mathrm{~mL}$ glass centrifuge tube wrapped with aluminum foil. The samples were then mixed at room temperature for $30 \mathrm{~min}$ on a mechanical orbital shaker and, after an addition of $10 \mathrm{~mL}$ of $0.1 \%(\mathrm{w} / \mathrm{v})$ Butylated Hydroxytoluene (BHT)-stabilized toluene, an additional 10 min-shaking was carried out. After centrifugation, the samples were placed in a refrigerator maintained at 2$6^{\circ} \mathrm{C}$ for $60 \mathrm{~min}$. One milliliter aliquot of the toluene upper layer was 1:25 diluted with methanol and tetrahydrofuran
(THF) (60:40), and immediately tested with HPLC analysis. A Shimadzu LC-10ADvp, SIL-10ADvp high-performance liquid chromatograph equipment, with SPD-10Avp and RF-10Axl detectors, was used for sample analyses; the HPLC pumps, auto sampler and detectors were controlled via Class vp 3.4 software. The analytical column was a Luna RP C18 (4.6 mm x $250 \mathrm{~mm}$, particle size $=5 \mathrm{~mm})$, provided with a guard column obtained from Chemtek Analytica. The column temperature was maintained at $30^{\circ} \mathrm{C}$. The lycopene isomer separation was carried out at a $1.2 \mathrm{~mL} / \mathrm{min}$ flow rate, using an isocratic elution with a mobile phase mixture of $90 \%$ methanol and $10 \%$ THF (O’Neil and Schwartz 1992). The injection volume was 10 $\mathrm{mL}$ and the $472 \mathrm{~nm}$ wavelength was used for absorbance detection of the lycopene. The data were analyzed using the Statistical Package for the Social Sciences (SPSS) 10.0-window program (1999). One-way variance analysis (ANOVA) was employed to identify significant differences between samples at $\mathrm{p} \leq 0.01$ significance level.

\section{Fruit color measurement}

Color measurements of tomatoes were made using a portable CR-400 tristimulus colorimeter (Minolta Chroma Meter CR 400, Osaka, Japan) and Spectra-Match software, set to $\mathrm{L}^{*}, \mathrm{a}^{*}, \mathrm{~b}^{*}$ mode. The colorimeter has a beam diameter of $8 \mathrm{~mm}$, three response detectors set at 0 viewing angle and a CIE standard illuminant $\mathrm{C}$ with diffuse illumination. Each fruit was measured twice, at two different sites on opposite sides of the equatorial region. A total of 10 tomatoes were assayed, both from WT and each transformed line, and three color readings were taken from each sample. $L^{*}$ indicates the lightness, ranging from black (0) to white (100); $\mathrm{a}^{*}$ specifies the amount of red and green tonality, on a green (-) to red (+) axis; and b* indicates the amount of blue and yellow tonality, on a blue (-) to yellow $(+)$ axis. The results were expressed as the ratio of red to green color $\left(\mathrm{a}^{*} / \mathrm{b}^{*}\right)$, hue angle value $\left[\mathrm{h}=\arctan \left(\mathrm{b}^{*} / \mathrm{a}^{*}\right)\right.$, where $0^{\circ}=$ red purple; $90^{\circ}=$ yellow; $180^{\circ}=$ bluish-green and $270^{\circ}=$ blue], saturation (or chroma) $\left[\mathrm{C}=\left(\mathrm{a}^{*} 2+\right.\right.$ $\left.\mathrm{b}^{*} 2\right)^{1 / 2}$ ] and tomato color index [TCI $=\mathrm{a}^{*} / \mathrm{L} *(\mathrm{a} * 2+$ b*2)1/2] (Shewfelt et al., 1988). 


\section{RESULTS}

\section{Development of transgenic plants}

The leaf explants were transferred to fresh selection medium MS2 after two days of co-cultivation on MS1 medium. One week later, some explants had grown larger and thicker, followed by shoots regeneration which gradually appeared from the edges of these explants. After one month, 138 shoots of 2-3 cm in length were cut off from the base of explants and placed on rooting medium MS3. After two weeks, 30 kanamycin-resistant plants developed normal roots on MS3. These 30 plants were transplanted to perlite for further molecular analysis and functional tests. Later, some plants were transferred to soil in greenhouse for seed production. The presence of transgenes in putative transgenic plants was first analyzed by PCR with specific primers to BrRZFPl gene. Among 30 transformants, 16 were found to be positive for the BrRZFP1 gene through PCR analysis (data not shown). Subsequently, to further confirm transgenic status of the BrRZFPl-positive plants and to determine the copy number of insertions in independent transgenic lines, the genomic DNA was digested with $B g l I I$ and hybridized with labelled $1.4 \mathrm{~kb} B r R Z F P 1$ gene probe. Southern analysis confirmed the integration of the BrRZFPl gene in the genome of some transgenic lines, including AT04, AT06, AT09, AT11 and AT17. The number of the BrRZFP1 gene insertions in transgenic lines varied from 1 to 3 , while the wild type plant did not show any hybridization signal (Fig. 1).

\section{Analysis of transgenic $T_{1}$ progenies}

$\mathrm{T}_{1}$ progenies derived from the independent primary transformants (AT04, AT09 and AT17) expressing BrRZFP1 gene were analyzed for the segregation patterns of the induced BrRZFPl gene by PCR analysis. The BrRZFPl gene in AT04 line except in the other two lines segregated at a ratio of $3: 1$ (Table 1), indicating the integration of the transgenes into tomato genomes in Mendelian manner.

\section{Evaluation of BrRZFP1-expressing plants for cold tolerance}

To assess cold stress damage on BrRZFP1-expressing plants, the Photosystem II (PSII) stability was measured to reflect the level of cellular damage after cold treatments. The ratio between the variable fluorescence $(\mathrm{Fv})$ and the maximum fluorescence (Fm) was used to estimate the quantum yield of the PSII photochemistry. The leaves from control and transformed plants were exposed to an excess

(A)

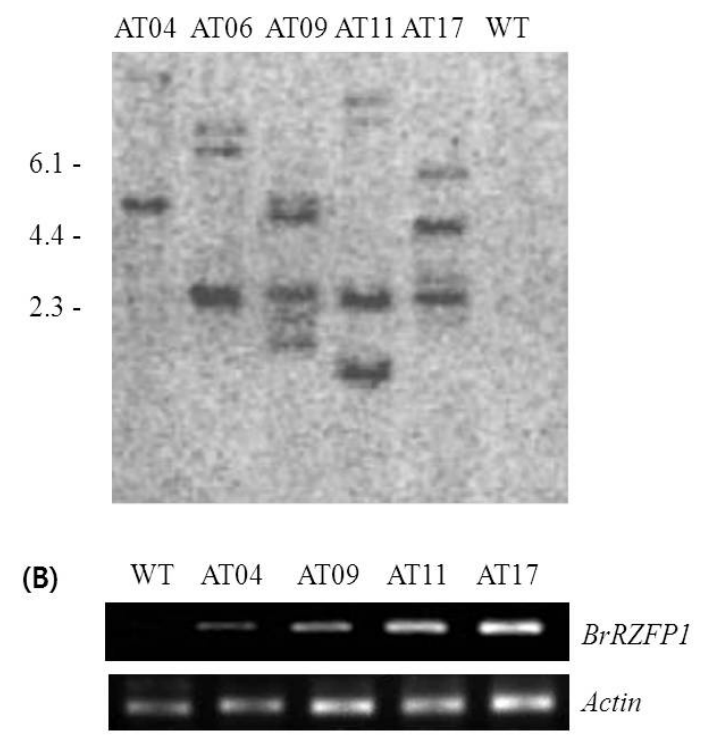

Fig. 1. Molecular analysis of BrRZFPl gene in transgenic tomato plants. (A) Southern hybridization, (B) RT-PCR analysis. 
of light energy $\left(750 \mu \mathrm{mol} \mathrm{m} \mathrm{m}^{2}\right)$ at low temperature $\left(4^{\circ} \mathrm{C}\right)$. $\mathrm{Fv} / \mathrm{Fm}$ values were measured at different times during treatment. The BrRZFP1-transformed plants exhibited values of $\mathrm{Fv} / \mathrm{Fm}$ comparable to that of the WT, indicating that the BrRZFPlexpression did not affect the PSII efficiency (Table 2). The cold treatment at high light intensity caused a marked inhibition of the PSII for both the WT and transgenic plants, as indicated by a decrease in the $\mathrm{Fv} / \mathrm{Fm}$ values from 0.8 up to 0.5 .

\section{Evaluation of BrRZFP1-expressing plants for drought tolerance}

To evaluate the resistance of transgenic lines to drought stress, 4-week-old plants were not watered for 16 days and RWC was measured every 4 days. The RWC of leaves in transgenic plants remained high during water deficit treatments. By contrast, a marked reduction in the water content was observed in the WT plants (Fig. 2). For the survival rate test, the water deficit was extended to 28 days

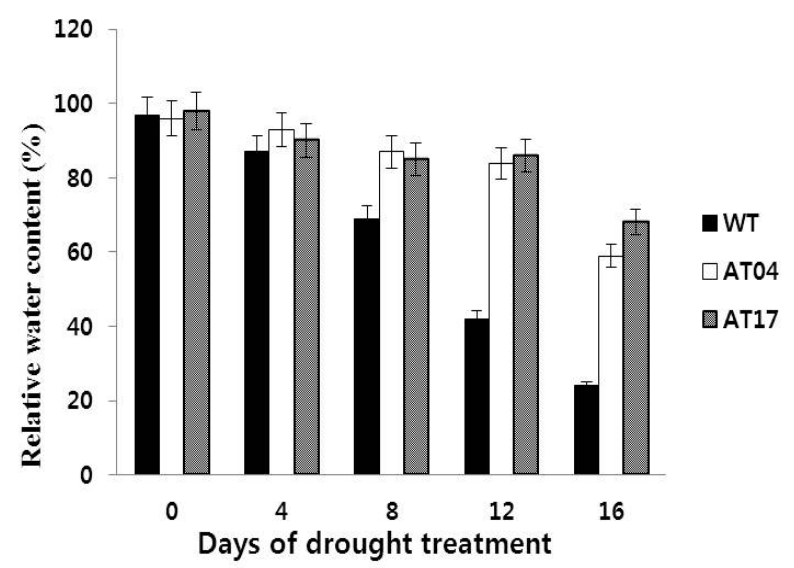

Fig. 2. Bioassay of relative water content (RWC) in $T_{1}$ transgenic tomato lines for drought stress tolerance. WT; wild type plant, AT04-AT17; transgenic lines. Data represent the means of ten replicates per line per treatment \pm standard error.

Table 1. Segregation of BrRZFPl gene $\mathrm{T}_{1}$ progenies of transgenic tomato lines.

\begin{tabular}{cccccc}
\hline \multirow{2}{*}{ Line } & Total assays & \multirow{2}{*}{$\begin{array}{c}\text { Expected } \\
\text { segregation ratio }\end{array}$} & BrRZFP1 & \multicolumn{2}{c}{ PCR for the BrRZFP1 gene } \\
\cline { 4 - 6 } AT04 & 60 & $3: 1$ & 43 & 17 & 0.35 \\
AT09 & 60 & $3: 1$ & 51 & 9 & 3.20 \\
AT17 & 60 & $3: 1$ & 53 & 7 & 5.68 \\
\hline
\end{tabular}

Table 2. Photosystem II inhibition by cold and high light treatment. Photoinhibition (evaluated as Fv/Fm) induced in detached leaves from 4-week old transgenic and WT tomato plants treated at $4^{\circ} \mathrm{C}$ and $750 \mu \mathrm{mol} \mathrm{m}^{2} \mathrm{~s}^{1}$.

\begin{tabular}{cccc}
\hline \hline & & Photoinhibition (Fv/Fm) & \\
\cline { 2 - 4 } & $1 \mathrm{~h}$ & $3 \mathrm{~h}$ & $6 \mathrm{~h}$ \\
\hline WT & 0.83 & 0.62 & 0.52 \\
AT04 & 0.81 & 0.67 & 0.53 \\
AT06 & 0.84 & 0.63 & 0.51 \\
AT09 & 0.82 & 0.68 & 0.54 \\
AT11 & 0.80 & 0.64 & 0.52 \\
AT17 & 0.81 & 0.65 & 0.51 \\
\hline
\end{tabular}


and then the plants were re-watered for 7 days. This set up was performed twice. In the first experiment, the survival rate was 9/20,15/20 and 14/20 for the WT and transgenic lines AT0 4 and AT17, respectively. In the second experiment, the survival rate was $7 / 20,15 / 20$ and $11 / 20$ for the WT and transgenic lines AT04 and AT17, respectively. All results observed indicate that transgenic lines are more resistant to drought stress than WT plants and that there is no significant different behavior between transgenic plants expressing the BrRZFPl gene driven by a constitutive or an inducible promoter. Since in Arabidopsis the overexpression of BrRZFPl increases the level of osmoprotectant compounds (Jung et al. 2013), we also measured the content of soluble sugars and proline in leaves of WT and 4-week-old transgenic tomato plants under normal and water deficit conditions. In normal growth conditions, the concentrations of sucrose, fructose and glucose were constitutively higher in transgenic lines with respect to WT (Table 3). In response to water deficit conditions, the soluble sugar content increased in all genotypes. In particular, values in WT were in all cases lower than those of transgenic plants, and AT04 line achieved the same levels of the AT17 line. The proline content in transformed tomato is not much higher than in WT plants under normal conditions; however, there is an increase in response to water stress treatment in both AT04 and AT17 with respect to WT plants (Table 3).

\section{Tomato fruit analysis}

To test if the use of the constitutive overexpression of the BrRZFP1 transcription factor modified the tomato fruit quality, we performed the analysis reported in Table 4. ${ }^{\circ}$ Brix is a measure of the total soluble solid percentage (chiefly fructose and glucose) increasing in turn with fruit color and ripeness: its value was higher in the transgenic fruits than in the WT ones. Also the lycopene content, in the transgenic lines freshly harvested ripe tomatoes, was slightly higher than in the WT samples.

Table 3. Soluble sugar and proline content in WT and transgenic tomato lines before and after 28 days of dehydration stress.

\begin{tabular}{ccccccccc}
\hline \hline & \multicolumn{2}{c}{$\begin{array}{c}\text { Glucose } \\
(\mu \mathrm{g} / \mathrm{mg} \mathrm{Fw})\end{array}$} & \multicolumn{2}{c}{$\begin{array}{c}\text { Fructose } \\
(\mu \mathrm{g} / \mathrm{mg} \mathrm{Fw})\end{array}$} & \multicolumn{2}{c}{$\begin{array}{c}\text { Sugar } \\
(\mu \mathrm{g} / \mathrm{mg} \text { Fw })\end{array}$} & \multicolumn{2}{c}{$\begin{array}{c}\text { Proline/ total } \\
\text { amino acid\% }\end{array}$} \\
\cline { 2 - 9 } & Before & After & Before & After & Before & After & Before & After \\
\hline WT & 0.91 & 1.43 & 1.03 & 2.27 & 0.34 & 0.42 & 1.92 & 5.64 \\
AT04 & 1.21 & 2.96 & 1.21 & 3.77 & 0.98 & 1.84 & 2.30 & 6.89 \\
AT06 & 1.31 & 2.98 & 1.89 & 3.88 & 0.91 & 1.86 & 2.12 & 7.27 \\
AT09 & 1.51 & 3.10 & 2.70 & 3.76 & 0.99 & 1.98 & 2.83 & 7.32 \\
AT11 & 1.43 & 3.01 & 2.04 & 4.42 & 1.23 & 2.01 & 2.69 & 7.21 \\
AT17 & 1.69 & 2.92 & 2.57 & 3.97 & 1.19 & 2.11 & 2.48 & 7.10 \\
\hline
\end{tabular}

Each value is the mean $(\mathrm{n}=5$ individual plants).

Table 4. Main fruit traits of wild type and transgenic tomato lines.

\begin{tabular}{ccccccc}
\hline \hline & $\begin{array}{c}\text { Weight } \\
(\mathrm{g})\end{array}$ & ${ }^{\circ}$ Brix & $\begin{array}{c}\text { Lycopene } \\
(\mu \mathrm{g} / \mathrm{g})\end{array}$ & $\mathrm{L}$ & $\mathrm{a}$ & $\mathrm{b}$ \\
\hline WT & 14.2 & 5.8 & 19.28 & 40.47 & 22.71 & 18.46 \\
AT04 & 16.3 & 5.9 & 24.32 & 39.66 & 20.86 & 19.88 \\
AT06 & 15.8 & 6.3 & 27.38 & 38.76 & 21.34 & 20.21 \\
AT09 & 14.9 & 6.5 & 24.88 & 39.44 & 22.74 & 19.86 \\
AT11 & 13.8 & 6.9 & 32.44 & 38.27 & 29.66 & 18.44 \\
AT17 & 12.9 & 6.3 & 27.68 & 36.99 & 24.58 & 19.01 \\
\hline
\end{tabular}




\section{DISCUSSION}

Transcription factors have been shown to play important roles in signal transduction and gene expression under plant stress responses to salt, cold and drought (Chen et al. 2002; Shinozaki et al. 2003; Bartels and Sunkar 2005; Yang et al. 2008). A better understanding of stress-regulated transcription factors through cloning and characterization will be highly valuable in improving plant stress tolerance (Wang et al. 2003). The C3HC4-type RING zinc finger proteins play important roles in a variety of plant processes, including regulation of growth and development, proteinprotein interactions and signaling networks (Freemont 1993; Borden et al. 1995; Tsuge et al. 2001; Wang et al. 2006). In addition, these transcription factors have been linked to abiotic stress processes for cold and salt (Lee et al. 2001; Xiong et al. 2002; Mukhopadhyay et al. 2004; Huang et al. 2011). Importantly, several studies have also linked RING domain containing proteins to E3 ubiquitin ligase activity and these same abiotic stress-regulated processes (Lyzenga and Stone 2011), e.g. zinc finger proteins such as ZFP1 from Artemisia desertorum (Yang et al. 2008), so additional experimentation is required to determine if BrRZFP1 may have an E3 ligase role. To further study these stress-related processes, the first $\mathrm{C} 3 \mathrm{HC} 4$ type RING zinc finger protein, $B r R Z F P 1$, from cold tolerant $B$. rapa was cloned and examined. We found that BrRZFP1 is expressed over a range of plant tissues, but at very high levels in roots during early development of germinating seedlings. This is the first report of BrRZFPI involvement in stress responses, following previous transcriptome analyses of $B$. rapa for abiotic stress responses genes (Lee et al. 2008; Yu et al. 2012). Interestingly, while several transcription factors were found to be stressregulated in these studies, few zinc finger protein were among those identified. We are unsure why BrRZFPl was not identified in these prior transcriptome analyses, possibly due to the incomplete nature of microarrays or genome sequence used. Nevertheless, it demonstrates that direct experimentation on genes of interest is an essential process. Like Arabidopsis (Jung et al. 2013), tomato transgenic plants overexpressing $B r R Z F P 1$ acquired a higher tolerance to drought stress. It is known that, under drought stress conditions, plants accumulate several compatible solutes, such as soluble sugars and proline, as a mechanism to improve tolerance to water deficit (Bonhert and Jensen 1996). Following drought treatment, an increase in the level of these osmolytes was observed in both WT and transgenic tomato plants, but levels accumulated by transgenics were always higher than those observed in WT. As far as free sugars are concerned, their content in $B r R Z F P l$ constitutively expressing plants was higher than in WT plants also under normal growth conditions. These results indicate that the improvement of drought tolerance in BrRZFP1 transgenics depends, at least partially, on the changes in the accumulated levels of compatible solutes. Contrary to the results obtained in Arabidopsis, the tomato BrRZFP1 transgenic plants did not appear to be more cold tolerant than the WT, in any tested condition. The different behavior between Arabidopsis and tomato could lie in the different selective pressure in response to different environments colonized by the two species. The tomato is a tropical plant and selection pressures could have caused the loss of the target genes in the cold pathway controlled by BrRZFP1. The results of Huang et al. (2008) point to the same direction, demonstrating that the tomato $Z F P$ region involved in freezing tolerance differs considerably from that of Arabidopsis: it is much smaller in size and potentially less diverse in function. Owing to the dietary relevance of tomato fruits, we tested the effect of the ZFPI transcription factor constitutive overexpression on the quality of transgenic tomato fruits. The results indicate a slight increase both in the lycopene and soluble solids content in transgenic plants. The other tested fruit characteristics were not significantly different between transgenic and control plants. In conclusion, the obtained data show that the BrRZFPl stress-response machinery is only partially conserved between tomato and Arabidopsis. The specificity and the degree of BrRZFPl activity depend on the host genomic background. This fact may represent a constraint in the use of transcriptional factors in the improvement of crop plants. On the other hand the use of heterologous transcription factors represents a good strategy to minimize possible mechanisms of transgene cosuppression during crop transformation. 


\section{ACKNOWLEDGMENTS}

This research was supported by Golden Seed Project (Center for Horticultural Seed Development, No. 21300304-1-SBC10), Ministry of Agriculture, Food and Rural Affairs (MAFRA), Ministry of Oceans and Fisheries (MOF), Rural Development Administration (RDA) and Korea Forest Service (KFS).

\section{REFERENCES}

Bartels D, Sunkar R. 2005. Drought and salt tolerance in plants. Crit. Rev. Plant Sci. 24: 23-58.

Bonhert JH, Jensen RG. 1996. Strategies for engineering water-stress tolerance in plants, Trends Biotechnol. 14: 89-97.

Borden KL, Boddy MN, Lally J, O'Reilly NJ, Martin S, Howe K, Solomon E, Freemont PS. 1995. The solution structure of the RING finger domain from the acute promyelocytic leukaemia proto-oncoprotein PML. EMBO J. 14: 1532-1541.

Chen M, Ni M. 2006. RFI2, a RING-domain zinc finger protein, negatively regulates CONSTANS expression and photoperiodic flowering. The Plant J. 46: 823-833.

Cheung MY, Zeng NY, Tong SW, Li FW, Zhao KJ, Zhang Q, Sun SS, Lam HM. 2007. Expression of a RING-HC protein from rice improves resistance to Pseudomonas syringae pv. Tomato DC3000 in transgenic Arabidopsis thaliana. J. Exp. Bot. 58: 4147-4159.

Cong L, Chai TY, Zhang YX. 2008. Characterization of the novel gene BjDREB1B encoding a DREbinding transcription factor from Brassica juncea L. Biochem. Biophys. Res. Commun. 371: 702-706.

Evenson RE, Gollin D. 2003. Assessing the impact of the green revolution, 1960-2000; Science 300: 758-762.

Freemont PS. 1993. The RING finger: a novel protein sequence motif related to the zinc finger. Ann. N.Y. Acad. Sci. 684: 174-192.

Freemont PS, Hanson IM, Trowsdale J. 1991. A novel cysteine-rich sequence motif. Cell 64: 483-484.

Gamborg OL, Miller RA, Ojima K. 1968. Nutrient requirement suspension cultures of soybean root cells. Exp. Cell Res. 50: 151-158.

Golldack D, Lüking I, Yang O. 2011. Plant tolerance to drought and salinity: stress regulating transcription factors and their functional significance in the cellular transcriptional network. P. Cell Rep. 30: 1383-1391.

Huang P, Ju HW, Min JH, Zhang X, Chung JS, Cheong HS, Kim CS. 2011. Molecular and physiological characterization of the Arabidopsis thaliana oxidationrelated Zinc Finger 2, a plasma membrane protein involved in $\mathrm{ABA}$ and salt stress response through the ABI2-mediated signaling pathway. Plant Cell Physiol. 53: 193-203.

Islam MM, Tani C, Watanabe-Sugimoto M, Uraji M, Jahan MS, Masuda C, Nakamura Y, Mori IC, Murata Y. 2009. Myrosinases, TGG1 and TGG2, redundantly function in $\mathrm{ABA}$ and MeJA signaling in Arabidopsis guard cells. Plant Cell Physiol. 50: 1171-1175.

Jung YJ, Lee IH, Nou IS, Lee KD, Rashotte AM, Kang KK. 2013. BrRZFP1 a Brassica rapa C3HC4-type RING zinc finger protein involved in cold, salt and dehydration stress. Plant Biol. 15: 274-283.

Kam J, Gresshoff P, Shorter R, Xue GP. 2007. Expression analysis of RING zinc finger genes from Triticum aestivum and identification of TaRZF70 that contains four RING-H2 domains and differentially responds to water deficit between leaf and root. Plant Sci. 173: 650-659.

Khush GS. 2001. Green revolution: the way forward. Nat. Rev. 2: 815-822.

Laity JH, Lee BM, Wright PE. 2001. Zinc finger proteins: new insights into structural and functional diversity. Curr. Opin. Struct. Biol. 11: 39-46.

Lee H, Xiong L, Gong Z, Ishitani M, Stevenson B, Zhu JK. 2001. The Arabidopsis HOS1 gene negatively regulates cold signal transduction and encodes a RING finger protein that displays coldregulated nucleo-cytoplasmic partitioning. Genes Dev. 15: 912-924.

Lee SC, Lim MH, Kim JA, Lee JS, Jin M, Kwon SJ, Mun JH, Kim YK, Kim HU, Hur Y, Park BS. 2008. Transcriptome analysis in $B$. rapa under the abiotic stresses using Brassica $24 \mathrm{~K}$ oligo microarray. Mol. Cells 26: 595-605.

Lyzenga WJ, Stone SL. 2011. Abiotic stress tolerance mediated by protein ubiquitination. J. Exp. Bot. 63: 599-616.

Ma K, Xiao J, Li X, Zhang Q, Lian X. 2009. Sequence and expression analysis of the C3HC4-type RING finger gene family in rice. Gene 444: 33-45.

Mattana M, Biazzi E, Consonni R, Locatelli F, Vannini C, Provera S, Coraggio I. 2005. Overexpression of Osmyb4 
enhances compatible solute accumulation and increases stress tolerance of Arabidopsis thaliana. Physiol. Plant 125: 212-223.

Mazzucotelli E, Mastrangelo AM, Crosatti C, Guerra D, Stanca AM, Cattivelli L. 2008. Abiotic stress response in plants: when post-transcriptional and post-translational regulations control transcription. Plant Sci. 174: 420-431.

Moore S. 1968. Amino acid analysis: aqueous dimethylsulfoxide as solvent for the ninhydrin reaction. J. Biol. Chem. 243: 6281-6283.

Mukhopadhyay A, Vij S, Tyagi AK. 2004. Overexpression of a zinc-finger protein gene from rice confers tolerance to cold, dehydration, and salt stress in transgenic tobacco. Proc. Natl. Acad. Sci. USA 101: 6309-6314.

Murashige T, Skoog F. 1962. A revised medium for rapid growth and bio assays with tobacco tissue cultures. Physiol. Plant. 15: 473-497.

O'Neil CA, Schwartz SJ. 1992. Chromatographic analysis of cis-trans carotenoid isomers, J. Chromatogr. 624: 235-252.

Pepper AE, Chory J. 1997. Extragenic suppressors of the Arabidopsis det1 mutant identify elements of floweringtime and light-response regulatory pathways. Genetics 145: 1125-1137.

Prestele J, Hierl G, Scherling C, Hetkamp S, Schwechheimer C, Isono E, Weckwerth W, Wanner G, Gietl C. 2010. Different functions of the $\mathrm{C} 3 \mathrm{HC} 4$ zinc RING finger peroxins PEX10, PEX2, and PEX12 in peroxisome formation and matrix protein import. Proc. Natl. Acad. Sci. USA 107: 14915-14920.

Saurin AJ, Borden KLB, Boddy MN, Freemont PS. 1996. Does this have a familiar RING? Trends Biochem. Sci. 21: 208-214.

Shewfelt RL, Thai CN, Davis JW. 1998. Prediction of changes in colour of tomatoes during ripening at different constant temperatures. J. Food Sci. 53: 1433-1437.

Shinozaki K, Yamaguchi-Shinozaki K, Seki M. 2003. Regulatory network of gene expression in the drought and cold stress responses. Curr. Opin. Plant Biol. 6: 410-417.
Tarantino D, Vianelli A, Carraro L, Soave C. 1999. A nuclear mutant of Arabidopsis thaliana selected for enhanced sensitivity to light-chill stress is altered in PSII electron transport activity. Physiol. Plant 107: 361-371.

Tran LS, Nakashima K, Shinozaki K, Yamaguchi-Shinozaki K. 2007. Plant gene networks in osmotic stress response: from genes to regulatory networks. Meth. Enzymol. 428: 109-128.

Tsuge T, Inagaki N, Yoshizumi T, Shimada H, Kawamoto T, Matsuki R, Yamamoto N, Matsui M. 2001. Phytochrome-mediated control of COP1 gene expression in rice plants. Mol. Genet. Genomics 265: 43-50.

Wang YS, Pi LY, Chen X, Chakrabarty PK, Jiang J, Lopez De Leon A, Liu GZ, Li L, Benny U, Oard J, Ronald PC, Song WY. 2006. Rice XA21 binding protein 3 is a ubiquitin ligase required for full Xa21mediated disease resistance. The Plant Cell 18: 36353646.

Xiong L, Schumaker KS, Zhu JK. 2002. Cell signaling during cold, drought, and salt stress. The Plant Cell 14: $165-183$.

Yang X, Sun C, Hu Y, Zhongping L. 2008. Molecular cloning and characterization of a gene encoding RING zinc finger ankyrin protein from drought-tolerant Artemisia desertorum. J. Biosci. 33: 103-112.

Yu S, Zhang F, Yu Y, Zhang D, Zhao X, Wang W. 2012. Transcriptome profiling of dehydration stress in the Chinese Cabbage (Brassica rapa L. ssp. pekinensis) by Tag sequencing. Plant Mol. Biol. Rep. 30: 17-28.

Zhang Y, Yang C, Li Y, Zheng N, Chen H, Zhao Q, Gao T, Guo H, Xie Q. 2007. SDIR1 is a RING finger E3 ligase that positively regulates stress responsive abscisic acid signaling in Arabidopsis. The Plant Cell 19: 1912-1929.

Zheng X, Chen B, Han B. 2009. Overexpression of a NAC transcription factor enhances rice drought and salt tolerance. Biochem. Biophys. Res. Commun. 379: 985-989. 